\title{
11 \\ Groundwater Management in
Drought Conditions Management in
Drought Conditions
}

\section{Eduardo Kruse \\ Museum of the National \\ University of La Plata \\ Saeid Eslamian \\ Isfahan University \\ of Technology}

11.1 Introduction

11.2 Groundwater as Reservoir...............................................................2276

11.3 Groundwater Use during Droughts ..............................................277

11.4 Groundwater in Water Management................................................2278

11.5 Summary and Conclusions ........................................................279

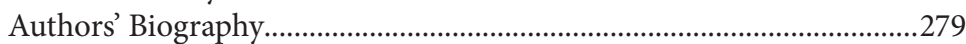

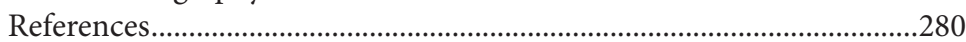

\begin{abstract}
This chapter analyzes the relevance that groundwater management acquires in drought conditions and discusses the role that it may have in the mitigation of the negative effects associated with such a phenomenon. The opportunities for groundwater exploitation constitute alternative water use, favored by the volume stored in aquifers in different regions. Drought events have increased lately, intensifying the requirement for groundwater, in particular for human consumption and agricultural use. The conjunctive use of surface water and groundwater is a technique of interest in many locations. During wet periods, the use of surface water prevails, leading to the recovery of the aquifer reserves, which are exploited more intensely during the dry periods. A groundwater reservoir appears as a strategic resource depending on its storage capacity, the availability of reserves, and its spatial distribution. Groundwater use entails a planned exploitation that takes into consideration environmental sustainability, based on the integrated management of the water resources. In order to do so, the key is a balanced use that avoids the excessive lowering of the groundwater levels (i.e., the depletion of the resource) and the deterioration of the chemical quality. An integrated management of the water resources in times of drought should be characterized by an adequate hydrogeological knowledge and their relationship with the natural ecosystems. An effective system to solve the problems resulting from droughts must implement preventive measures that would make it possible to count, well in advance, on the necessary infrastructure for groundwater supply, as well as monitoring and maintenance, which guarantee its availability if necessary.
\end{abstract}

\subsection{Introduction}

Droughts are natural catastrophes with dire consequences for society, especially due to the impact on the drinking water supply and the decrease in agricultural productivity. Unlike other catastrophes, such as floods, hurricanes, or tornadoes, whose distributions are rather restricted on a spatial and temporal 
scale, drought regimes are more difficult to determine as regards their duration, and their area of influence may be much larger. This leads to greater difficulties in defining the estimation and prediction methods.

Droughts have been classified into different types [18], such as meteorological (lack of precipitation), agricultural (lack of soil moisture), or hydrological drought (reduction in runoff or groundwater levels) [19].

For a given period of time, water deficiency may constitute a different type of drought depending on the effects taken into consideration. A prolonged dry period may significantly reduce crop yield (agricultural drought) due to the shortage in soil moisture [8], but have little effect on the storage of the groundwater recharged in previous periods. Conversely, during a dry period extended in time due to a lack of groundwater recharge, the water tables may be lowered, decreasing the reserves (hydrological drought), which may contrast with the occurrence of precipitations during the time period considered [12]. Examples may be given of the co-occurrence of agricultural drought due to the limited soil water reserves and of waterlogging caused by the rise in the water tables recharged in earlier times [13].

If groundwater is part of the water cycle, it constitutes an areally limited, renewable resource naturally recharged by the infiltration of rainwater or surface water. It is in continuous motion in an aquifer medium, though generally slowly, until it discharges through springs, rivers, or subterraneously into the sea; therefore, many aquatic and terrestrial ecosystems depend upon it.

The unity of the water cycle and the need for integrated water management entail taking groundwater into consideration during drought periods, given the role that it may have in the mitigation of the impact exerted by the phenomenon. It is precisely the objective of this chapter to define the importance of groundwater management in drought conditions.

\subsection{Groundwater as Reservoir}

An aquifer constitutes a subterranean water reservoir with different possibilities for use and exploitation, which is why they are a source of supply both during normal periods and droughts.

Groundwater systems tend to respond more slowly to short-term variability in climatic conditions than surface water. As a result, the estimation of groundwater storage and its related model simulations are generally based on average conditions, such as mean annual recharge or mean annual discharge into rivers. This use of the average conditions may be adequate in normal circumstances, but the results may be altered during droughts. Therefore, the simulation of extreme scenarios of water shortage is required.

Groundwater exploitation underwent extensive development in the second half of the twentieth century, which transformed groundwater into a significant source to mitigate the consequences of droughts. Experience suggests that traditionally such mitigation is associated with the construction of hydraulic infrastructure, such as surface reservoirs or canals for inter-basin water transfer.

In order to exploit groundwater during periods of droughts, it is necessary to take advantage of the possibilities for water transfer and storage that aquifers have to offer. The size and inertia of most aquifers cause them to function as large reservoirs with stored volumes several times larger than the annual recharge they receive [15].

The occurrence in different regions of groundwater reservoirs that store important volumes and whose exploitation is minimal is a practical alternative for drought mitigation.

On the other hand, in those regions where the groundwater levels have been drawn down significantly by exploitation before the drought, groundwater may fulfill a different role when dealing with droughts. Intensive exploitation may cause the water level in lakes and the runoff in streams and other water bodies to be below the limits during droughts [11], which constitutes an additional problem in such a situation.

The increase in groundwater use may continue after a drought, since constructing wells and setting up the infrastructure to supply groundwater may require substantial investment. Therefore, a drought might bring about an unexpected permanent change in the level of groundwater development.

The effect of possible long-term climate changes, including changes in the average conditions and climate variability, should also be considered [3,14]. Climate change could affect groundwater sustainability in 
several ways, including changes in recharge, longer-lasting droughts, char in evapotranspiration, and the

AQ1 possibility of an increasing water demand. Shallow aquifers, which suppl $D$ t of the water flow in streams, lakes, wetlands, and springs, are the part of the groundwater system most sensitive to climate change.

\subsection{Groundwater Use during Droughts}

Water scarcity is a phenomenon that is becoming more frequent and alarming, and it affects different regions in the world. The number of drought events has grown, their severity has increased in the last 30 years, and-as previously mentioned-according to the climate change predictions, problems such as whortage and droughts could be exacerbated [23,24].

circumstantial use of groundwater due to a lack of water availability during droughts should also be associated with an increase in its exploitation, related to a larger demand brought about by the transfor mation of agriculture from rainfed to irrigated systems, and by an increase in human population.

Groundwater pollution is much more difficult to abate than surface pollution because groundwater can move great distances through unseen aquifers. Pollutants and contaminants can be removed from groundwater by applying various techniques, thereby making it safe for use. Groundwater treatment techniques span biological, chemical, and physical treatment technologies. Nanotechnology is being used to develop solutions to different problems in groundwater quality. Nanoparticles can be used to convert the contaminating chemical through a chemical reaction to make it harmless [7].

The pollution hazard of an activity will be greater in certain hydrological, geological, and soil situations than in others. When we consider the level of risk from any given activity and want to ascertain its acceptability, we have to assess the total exposure of the groundwater system to that hazard. Vulnerability maps [21] are usually a significant element of the risk assessment.

Regions that satisfy their demand by using surface water generally have a hydraulic infrastructure with regulation capacity that allows them to guarantee the supply in normal climatic conditions, but during drought periods-when significant supply failures occur-they could be affected. Such a situation could be alleviated if groundwater were part of the exploitation system, since groundwater reserves are less affected by droughts in the short and medium term due to the characteristics and hydraulic properties of aquifers.

In such cases, the role of groundwater has generally been a quick-fix solution to the problematic situation, but not as part of an integrated plan for a supply system, leaving its resolution up to more conventional operations. The proposal should include groundwater as another element in the regulation systems, taking into consideration that it is a resource whose availability is only temporarily affected by the consequences of an important decrease in precipitations.

Experience shows that in those regions that only depend on groundwater for supply, an overexploitation during drought periods may have a negative impact, even though groundwater constitutes a strategic resource in such situations.

In such regions, groundwater is more susceptible to the impact of drought, due to a reduction in natural or artificial recharge, but essentially because such conditions cause an increase in groundwater exploitation, with more extraction to compensate for the shortage in water supply. Although there may be groundwater management programs, in many areas there is no control that leads to restricting or prohibiting any groundwater pumping. Therefore, an increase in pumping may have negative consequences, including the drying of wells, the occurrence of subsidence, a decrease in water quality, saline intrusion, and the progressive depletion of the source [1]. As a result, apart from leaving the problem unsolved, it poses an excessive, unjustified economic burden.

Artificial recharge with rainwater or reclaimed water is the practice of increasing by artificial means the amount of water that enters a groundwater reservoir. This includes, for example, direction of water to the land surface through canals, irrigation furrows or sprinkler systems, and injection of water into the subsurface through wells.

The combined or alternating use of surface water and groundwater, which has been implemented in many regions [22], should have a much more significant role in the future [2]. The experience of developed 
countries, such as the United States [16], regarding such a practice shows that, though necessary, it takes time for it to prevail.

From a practical standpoint, it is possible to find an increasing number of examples of the importance of groundwater in drought management. This concept was put into practice in the southeastern United States (California) and also in Spain [4]. In each case, the technical aspects of the aquifer must be studied in order to find the most adequate type of recharge and storage, as on many occasions there are underlying economic, legal, and political problems. This may be the reason why the conjunctive use has not been implemented in a planned, supervised, and controlled manner in many locations.

This practice has been in use in many places worldwide. During wet years, surface water is used and the aquifer is allowed to recover in a natural way, whereas the "natural" groundwater is only extracted in the dry years. This type of solution has been applied in ${ }^{\text {na }}[15,17]$, and for a long time it has

AQ3 been demanded in order to solve problems in a rational way. Seid and semiarid areas, to reduce the impacts of persistent intraseasonal drought and also to reduce flood damaging, rainwater storage is a prerequisite that keeps water from evapotranspiration, increases groundwater level, and decreases flood hazards modification to exchange between surface water and groundwater through flood spreading, dams, etc. [10].

\subsection{Groundwater in Water Management}

The use of groundwater to mitigate the effects of droughts will be effective if it is developed on the basis of early planning, since it is an essential aspect to maintain the reliability and sustainability of the resource. The components of the plan must include a management chemical quality, and surface water-groundwater interaction

The strategic character of a groundwater reservoir during periods of droughts is particularly connected to characteristics such as:

- Its storage capacity and inertia in recharge processes

- Availability (it is not significantly affected in the short and medium term by a decrease in precipitations)

- Spatial distribution (occurrence in the proximity of the region to be supplied)

- Water reserves (which may be exploited in a planned manner)

Groundwater use does not entail the mining of the resource but a planned exploitation, taking into consideration environmental sustainability.

The operational procedures may be summarized in two phases:

1. Temporary exploitation of groundwater reserves, which causes their decrease and the subsequent lowering of water table and piezometric levels

2. Reserve recovery (natural or artificial recharge) after a drought, with an increase in recharge and a rise in the water table and piezometric levels

The objective of the sustainable use of water should be an integrated approach [9], taking into consideration the conjunctive use of surface water and groundwater and paying attention to both quality and quantity, based on their complementary nature.

This conjunctive use has been implemented in different ways, although it is commonly associated with the use of the surface water surplus to recharge aquifers artificially whenever precipitations make it possible and the extraction of water from the aquifers in times of drought. On other occasions, the natural, alternating use of surface water and groundwater is enough, which prevents the problems brought about by the use of artificial recharge, especially the economic ones.

A key criterion is to find a balance in groundwater use that prevents the lowering of water table and piezometric levels in the long term (exploitation) and a rise in the levels (recharge), along with the threat of waterlogging and salinization of the land. 
This concept includes the use of the aquifer as a reservoir, contributing to an increase in the water regulation capacity and providing a better response to the possible drought periods. This solution is flexible due to the spatial distribution of aquifers, which entails adaptability to different situations, such as a pipeline or hydraulic infrastructure.

The conjunctive magagement of surface water and groundwater resources is necessary to mitigate the impact of drought $\Omega$ s requires a multidisciplinary approach that develops coupled models of surface water and groundwater flow in which the detailed hydrogeological characteristics (hydrodynamics and hydrochemistry) of the study area are taken into consideration. A historical series of the groundwater levels is also important for the proper calibration of the models [20].

In order to deal with the situations resulting from droughts, it is necessary to have a detailed knowledge of the following:

- Hydrogeological characteristics and estimation of the water reserves available in aquifers located near the area affected by periodical droughts

- Conditions of the aquifers to be used as regulation reservoirs

- Storage capacity of the aquifers

- Adaptation possibilities of the groundwater system for artificial water recharge

The cost should include well construction, pumping equipment, water conveyance infrastructure, monitoring systems, and system maintenance. Besides, it should include programs for the improvement of the hydrogeological knowledge, as well as the protection and management of aquifers and groundwater.

A hydrological plan considering droughts requires a good knowledge of the hydrogeology and its relationship with the related natural ecosystems, which will make it possible to overcome the problems derived from such adverse climatic conditions. An efficient system to solve these problems should implement preventive measures - that is to say that the necessary infrastructure should be available in advance-keep records, and monitor, in order to guarantee their availability if necessary.

\subsection{Summary and Conclusions}

Groundwater may have a strategic role in overcoming drought periods. However, there is no unique solution to mitigate the consequences of droughts. An integrated management of surface water and groundwater (conjunctive use) is required, since it is unlikely for the problem to be solved in an isolated manner. An adequate hydrological plan integrating both water sources is essential in the mitigation of the consequences of droughts.

Knowledge of the systems affected by drought situations, especially with regard to water supply and demand, makes it possible to act preventively, which constitutes an essential tool to face such conditions. This leads to securing the infrastructure that would guarantee the availability of water when needed.

As regards groundwater, it is essential to quantify the storage capacity of aquifers, as well as to assess the conditions for their incorporation into the exploitation systems, the selection of an adequate recharge system if necessary, and the monitoring and maintenance of the operations involved in the introduction of the system.

The combined use of surface water and groundwater constitutes a tool to be taken into consideration in regions subjected to periodical droughts.

\section{Authors' Biography}

Eduardo Kruse is professor of hydrology at the Facultad de Ciencias Naturales y Museo (School of Natural Sciences and Museum) of the Universidad Nacional de La Plata (National University of La Plata), senior researcher at CONICET (National Scientific and Technical Research Council), and director of the Centro de Investigaciones y Transferencia del Noroeste de la Provincia de Buenos Aires (Research and Transference Centre of Northwestern Buenos Aires Province) in Argentina. His area of interest is related 
to groundwater hydrology and environmental risks. He has led research teams that developed projects at an international level. He is the author of more than 200 articles, published in professional journals and books, as well as of chapters in books, conference proceedings, and technical specifications. His activity in human resource training includes the supervision of postgraduate theses (master's and doctoral degrees).

Saeid Eslamian is full professor of water system engineering in the Department of Water Engineering at Isfahan University of Technology, Iran, since 1995. He received his PhD from Civil and Environmental Engineering School of University of New South Wales, Australia, under the supervision of Professor David Pilgrim. His research focuses mainly on water resources planning, management, and sustainability and statistical and environmental hydrology in a changing climate. Formerly, he was a visiting professor at Princeton University, USA, and University of ETH, Zurich, Switzerland. On the research side, he started a research partnership in 2014 with McGill University, Canada. He has contributed to more than 500 publications in journals, books, or as technical reports. He is the founder and chief editor of both the International Journal of Hydrology Science and Technology (Scopus, Inderscience) and the Journal of Flood Engineering. Professor Eslamian is also associate editor of Journal of Hydrology (Elsevier) and the journal Ecohydrology and Hydrobiology (Elsevier). He has authored more than 150 book chapters and books. Recently, Professor Eslamian published eight handbooks with Taylor \& Francis Group (CRC Press) as chief editor: A three-volume Handbook of Engineering Hydrology (2014), Urban Water Reuse Handbook (2015), A three-volume Handbook of Drought and Water Scarcity (2016), and Underground Aqueducts Handbook (2016).

\section{AQ4 References $Q$}

1. Bartolino, J.R. and Cunningham, W.L. 2003. Ground-water depletion across the nation. USGS Fact Sheet-103-03. U.S. Department of the Interior. U.S. Geological Survey, Reston, VA, November 2003.

2. Castle, S.L., Thomas, B.F., Reager, J.T., Rodell, M., Swenson, S.C., and Famiglietti, J.S. 2014. Groundwater depletion during drought threatens future water security of the Colorado River Basin. Geophysical Research Letters, 41: 5904-5911. doi:10.1002/2014GL061055.

3. Cole, G. and Marsh, T. 2006. The impact of climate change on severe droughts. Environment Agency, Bristol, U.K. Science Report: SC040068/SR1. 1844326144.

4. Custodio, E. 2002. Aquifer overexploitation: what does it mean? Hydrogeology Journal, 10: 254-277.

5. Department of Water Resources. 2014. Public update for drought response groundwater basins with potential water shortages and gaps in groundwater monitoring. Technical Report. The Resources Agency State of California, Sacramento, CA.

6. Eslamian, S.S., Shaeri Karimi, S., and Eslamian, F. 2011. A country case study comparison on groundwater and surface water interaction. International Journal of Water, 6(1/2): 117-136.

7. Eslamian, S., Malekian, R., and Amiri, M.J. 2014. Environmental nanotechnology. In: Eslamian, S. (ed.), Handbook of Engineering Hydrology. Vol. 3: Environmental Hydrology and Water Management. Taylor \& Francis Group, CRC Press, Boca Raton, FL, Chap. 6, pp. 105-118.

8. Forte Lay, J.A., Kruse, E., and Aiello, J.L. 2007. Hydrologic scenarios applied to the agriculture management of the northwest of the Buenos Aires Province (Argentina). Geojournal, 70(4): 263-271.

9. Foster, S. and Ait-Kadi, M. 2012. Integrated water resources management (IWRM)-How does groundwater fit in? IAH Hydrogeology Journal, 20: 415-418.

10. Ghazavi, R., Vali, A.B., and Eslamian, S. 2012. Impact of flood spreading on groundwater level variation and groundwater quality in an arid environment. Water Resource Management, 26(6): 1651-1663.

11. Hughes, J., Petrone, K., and Silberstein, R. 2012. Drought, groundwater storage and stream flow decline in southwestern Australia. Geophysical Research Letters, 39: L03408. doi:10.1029/2011GL050797. 
12. Kruse, E., Forte Lay, J.A., Aiello, J.L., Basualdo, A., and Heinzenknecht, G. 2001. Hydrological processes on large flatlands. Case study: Northwest region of Buenos Aires Province (Argentina). Hydrological Sciences, 267: 531-536.

13. Kruse, E., Forte Lay, J.A., and Aiello, J.L. 2006. Water table fluctuations: An indicator of hydrologic behavior in the Northwest region of Buenos Aires Province (Argentina). Hydrological Sciences, 302: 91-97.

14. Kuss, A. and Gurdak, J. 2014. Groundwater level response in U.S. principal aquifers to ENSO, NAO, PDO, and AMO. Journal of Hydrology, 519: 1939-1952.

15. Llamas, M.R. 2000. Some lessons learnt during the drought of 1991-1995 in Spain. In: Vogt, J.V and Somma, F. (eds.), Drought and Drought Mitigation in Europe. Kluwer Academic Publisher 2 ,5 pp. $253-264$.

16. Llamas, M.R. and Custodio, E. (eds.) 2003. Intensive Use of Groundwater. Challenges and Opportunities. Balkema Publishers, Rotterdam, the Netherlands, 478pp.

17. Lluria, M.R. 2009. Successful application of Managed Aquifer Recharge in the improvement of the water resources management of semi-arid regions: Examples from Arizona and the Southwestern U.S.A. Boletín Geológico y Minero (España), 120(2): 111-120.

18. Mishra, A.K. and Singh, V.P. 2010. A review of drought concepts. Journal of Hydrology, 391(1): 202-216.

19. Mishra, A.K. and Singh, V.P. 2011. Drought modeling-A review. Journal of Hydrology, 403(1): 157-175.

20. Mussá, F., Zhou, Y., Maskey, S, Masih, I., and Uhlenbrook, S. 2015. Groundwater as an emergency source for drought mitigation in the Crocodile River catchment, South Africa. Hydrology and Earth System Sciences, 19: 1093-1106.

21. Saatsaz, M., Sulaiman, W.N.A., and Eslamian, S.S. 2011. GIS DRASTIC model for groundwater vulnerability estimation of Astaneh-Kouchesfahan Plain, Northern Iran. International Journal of Water, 6(1/2): 1-14.

22. Sahuquillo, A. 1991. La utilización conjunta de aguas superficiales y subterráneas en la mitigación de los efectos de la sequía. Jornadas sobre las sequías. Revista de la Real Academia de Ciencias Exactas, Físicas y Naturales, Madrid, Spain, Tomo LXXXV, pp. 275-291.

23. Spinoni, J., Naumannb, G., Vogta, J., and Barbosaa, P. 2015. The biggest drought events in Europe from 1950 to 2012. Journal of Hydrology: Regional Studies, 3: 509-524.

24. Thomsen, R. 1998. Future droughts, water shortages in parts of Western Europe. The Second International Conference on Climate and Water, Espoo, Finland. 


\section{Author Queries}

[AQ1] Please check if edit to sentence "Shallow aquifers..." is okay.

[AQ2] Please check sentence "The circumstantial..." for clarity.

[AQ3] Please check if latter part of sentence "In arid and semiarid áreas..." is complete.

[AQ4] Please cite Refs [5,6] in text.

[AQ5] Please provide publisher location for Ref. [15]. 